\title{
Formação de professores para o ensino remoto: Uma intervenção realizada no município de Riacho de Santana/RN
}

\author{
Teacher training for remote education: An intervention carried out in the municipality of Riacho \\ de Santana/RN
}

Formación del profesorado para la educación a distancia: Una intervención realizada en el municipio de Riacho de Santana/RN

\section{Resumo}

O ano de 2020 se encontra marcado por uma intensa política de isolamento social em decorrência do COVID-19. Contudo o desenvolvimento tecnológico tem contribuído para os diversos setores, entre estes o ensino, através das Tecnologias de Informação e Comunicação (TICs), influenciando positivamente na aprendizagem e fortalecendo os processos de ensino, proporcionando aos indivíduos distantes do ambiente educacional, uma possibilidade de obter conhecimento, assim como aos que desejam uma nova qualificação, uma alternativa de acesso a diversos conteúdos de forma remota. Abordando a utilização das ferramentas tecnológicas, a presente pesquisa visa a melhoria qualitativa do ensino e da aprendizagem, mediante ao distânciamento social, por meio de uma qualificação de docentes. Os recursos utilizados foram os softwares Vegas Pro 17, OBS Studio e 4k download, que auxiliam na gravação e edição de vídeoaula, contribuindo para que a educação a distância ocorra de forma mais eficaz. Com a formação os docentes foram capazes de planejar, gravar e editar videoaulas que seram compartilhadas aos discentes, atuando como encaminhamentos metodológicos mais interativos e produtivos.

Palavras-chave: COVID-19; Educação à distância; Tecnologias de informação e comunicação.

\begin{abstract}
The 2020 year is marked by an intense policy of social isolation because of COVID-19. However, technological development has contributed to different areas, including education, through the Information and Communication Technologies (TICs), influencing positively the processes of teaching and learning, providing individuals far from the educational environment, a possibility of learning, as well as those who want a new qualification, an alternative to access various contents. Addressing the use of technological tools, the present paper aims at the qualitative improvement of education and learning, during the social distancing, through the qualification of teachers. The resources used were the softwares Vegas Pro 17, OBS Studio and $4 k$ download, that assist in recording and editing video lessons, contributing to distance education to take place more effectively. With the training, teachers were able to plan, record and edit video classes that will be shared with students, acting as more interactive and productive methodological approaches.
\end{abstract}

Keywords: COVID-19; Distance learning; Information and communication technologies. 


\section{Resumen}

El año 2020 está marcado por una intensa política de aislamiento social como consecuencia del COVID-19. Sin embargo, el desarrollo tecnológico ha contribuido a que los diversos sectores, incluida la educación, a través de las Tecnologías de la Información y la Comunicación (TIC), influyan positivamente en el aprendizaje y fortalezcan los procesos de enseñanza, brindando a las personas que se encuentran alejadas del entorno educativo, la posibilidad de obtener conocimientos, así como aquellos que quieran una nueva titulación, una alternativa para acceder a diversos contenidos de forma remota. Abordando el uso de herramientas tecnológicas, la presente investigación tiene como objetivo la mejora cualitativa de la enseñanza y el aprendizaje, a través de la distancia social, a través de una calificación de los docentes. Los recursos utilizados fueron Vegas Pro 17, OBS Studio y el software de descarga 4k, que ayudan a grabar y editar lecciones en video, contribuyendo a que la educación a distância ocurra de manera más efectiva. Con la capacitación, los docentes pudieron planificar, grabar y editar video clases que serán compartidas con los estudiantes, actuando como enfoques metodológicos más interactivos y productivos.

Palabras clave: COVID-19; Educación a distancia; Tecnologías de la información y la comunicación.

\section{Introdução}

O novo coronavírus, denominado pela Organização Mundial da Saúde (OMS) de SARS-CoV-2, atingiu diversos países em consequência do seu alto grau de transmissibilidade. Ele é responsável por causar o COVID-19, dando início a uma epidemia de grande porte, segundo Garcia e Duarte (2020), na ausência de imunidade prévia na população humana, bem como de alguma vacina efetiva, o crescimento do número de casos é exponencial. De acordo com Bueno e Gama (2021), é necessário um diálogo sobre este vírus que já matou inúmeras pessoas e que tem afastado as pessoas do convívio social.

Segundo Appenzeller et al. (2020), a pandemia apresenta um impacto mundial na população, tendo consequências devastadoras em curto e o distanciamento social tornou-se um dos pilares principais para evitar a sobrecarga do sistema de saúde. Para Lewnard e Lo (2020), na ausência de qualquer intervenção farmacêutica, a estratégia mais usada contra a expansão da doença consiste em reduzir a interação entre pessoas infectadas e suscetíveis. Neste sentido, Anderson et al. (2020) afirmam que a solução para a mitigação é o isolamento vindo a interromper reuniões em massa, fechar unidades educacionais e até isolar famílias, vilas ou cidades. Para Carcamo, Stumpf e Mariot (2020, p. 114):

Governos de diferentes países vêm utilizando o fechamento das instituições de ensino como estratégia contra o alastramento da COVID-19. No Brasil, aparentemente, algumas instituições de ensino, como universidades e Institutos Federais, possuem maior potencial de veiculação de doenças infectocontagiosas, devido a características comuns dessas instituições, como alunos de faixas etárias e condições socioeconômicas variadas, atendimento a municípios do entorno de onde estão localizadas e presença de casas do estudante, alojamentos e restaurantes comunitários. (Carcamo, Stumpf \& Mariot, 2020, p. 114)

Visando conter a disseminação dessa pandemia, segundo a UNESCO, parte dos Governos optaram pelo fechamento temporário das instituições de ensino, impactando em mais de $60 \%$ dos estudantes, a nível mundial. Neste sentido, devido ao bloqueio do espaço físico da escola, o ensino remoto se tornou uma alternativa.

O desenvolvimento tecnológico tem contribuído para que um maior número de indivíduos tenha acesso aos diversos tipos de comunicação e educação. Para continuidade dos processos educativos, o ensino que remoto, que utiliza elementos da Educação a Distância $(\mathrm{EaD})$, tem sido uma alternativa visto que as pessoas não precisam frequentar os locais de aula.

Castaman e Szatkoski (2020), enfatizam as concepções de alguns autores clássicos: segundo Peters (1973), educação a distância é um método indireto de compartilhar conhecimentos, além de habilidades e atitudes, com um grande número de discentes por meio da reprodução de materiais técnicos. Por sua vez, Chaves (1999), caracteriza a forma do ensino a distância por meio do distanciamento físico, juntamente com o uso das Tecnologias de Informação e Comunicação (TICs). A Associação Brasileira de Educação a Distância (Abed, 2008), define EaD como a modalidade de educação em que as atividades que caracterizam o ensino-aprendizagem são desenvolvidas sem que alunos e professores estejam presentes no mesmo lugar. 
Assim, a forma do Ensino a distância engloba a separação física com o uso das TICs. Vieira et al. (2016) afirma que um ponto relevante dessa modalidade é o acesso ao conteúdo independentemente do local e horário, sem o comprometimento de estar presente em uma sala de aula.

Ao adotar essa modalidade de ensino, segundo Arruda (2020), o docente deve estar preparado para as dificuldades em manter a concentração do aluno e tornar o ambiente interativo. Então, existe uma necessidade de modificar as estratégias empregadas nas metodologias, contribuindo para o desenvolvimento da nova modalidade de ensino. Estas estratégias podem ser conduzidas pelas TICs que proporcionam diversas oportunidades para ensinar e aprender. Para Mourão, Araújo e Silva (2019, p. 11):

[...]as TICs permitem profundas mudanças no âmbito educacional, mas também sociais e econômicas, possibilitando a expansão de nossas fontes intelectuais/acadêmicas. A Internet surge como facilitadora de informações, gerando diferentes ferramentas e expandindo as escolhas dos sujeitos, que se associam por meio de seus gostos e interesses. (Mourão, Araújo \& Silva, 2019, p. 11)

Por mais que as TICs já possuam um papel significativo no cenário educacional, por parte de alguns profissionais, é notável o despreparo em lidar com esse método de ensino, visto que nem todos docentes possuem acesso. Sengundo Rosa e Cecílio (2010), alguns docentes afirmam não apresentar formação para a utilização pedagógica das TICs. Muitas instituições não apresentam condições físicas, materiais e técnicas que possibilitem ao aluno o acesso a essa tecnologia. Contribuindo para o déficit de conhecimento sobre a capacidade dessa ferramenta.

Para alguns educadores, a utilização das mídias no ambiente escolar é de influência positiva em vários aspectos, entre estes o seu uso como ferramenta pedagógica. Fernandes et al. (2020), afirma que a utilização das TICs contribui para uma melhor qualidade de ensino, possibilitando ao aluno participação na aula interagindo com o professor, intensificando a compreensão dos alunos. No entanto, quando utilizada de forma mecanizada, essa ferramenta contrapõe o seu objetivo principal, a produção de conhecimentos, principalmente, por meio da Internet (Soares, 2017).

Para Limeira (2017), a principal dificuldade está na forma de abordagem da tecnologia, de modo a alcançar o objetivo, sem causar danos pedagógicos ou cognitivos. A abordagem tecnológica proporciona mudanças sociais que influem na educação, contribuindo para o enriquecimento de conhecimento.

Apesar de algumas crianças e jovens estarem naturalmente inseridas no ambiente tecnológico, as instituições junto ao corpo docente, não devem impedir a integralização desse elemento no ambiente escolar, pelo contrário, deve reinventar o seu uso, abordando a tecnologia de modo que o aluno aprenda o mais igualmente possível, contribuindo para a aprendizagem do aluno. As TICs tratam-se de uma ferramenta de ensino e aprendizagem, que além de possuir utilidades no ambiente escolar, é uma solução para o ensino a distância.

Quanto ao ensino remoto, ele é uma possibilidade de continuidade dos processos educativos utilizando os elementos da educação a distância, tais como as TICs. Para Rondini, Duarte e Pedro (2020, p. 43), "o ensino remoto emergencial tornouse a principal alternativa de instituições educacionais de todos os níveis de ensino, caracterizando-se como uma mudança temporária em circunstâncias de crise". Esse formato de ensino é uma novidade, é requerido uma familiarização dos docentes com as ferramentas e metodologias capazes de provocar interação sem o contato presencial.

Para Feitosa et al. (2020, p.61)

Como o ensino remoto foi algo inesperado, professores que não estavam familiarizados com metodologias digitais, tais como web conferências e videoaulas, podem apresentar resistências para aceitarem a nova forma de ensinar e aprender devido a dificuldades vivenciadas. (Feitosa et al. 2020, p.61) 
Considerando todo o cenário decorrente do novo coronavírus, o presente trabalho tem como problematização: Como o uso dos softwares podem auxiliar no ensino remoto? Partes das dificuldades estão associadas ao manuseio dos dispositivos eletrônicos, como softwares de gravação e edição de vídeos, assim como as práticas pedagógicas, visto que incide sobre a equipe de professores a responsabilidade de manter o aluno estimulado e concentrado.

Desse modo, considerando os desafios existentes no ensino dentro do EaD e o contexto tecnológico, o presente trabalho apresenta os seguintes objetivos: A formação dos docentes para o ensino remoto e a utilização das TICs como agente potencializador do aprendizado dos discentes no ensino remoto. Sucedeu-se a abordagem dos softwares Vegas Pro 17, OBS Studio e $4 \boldsymbol{k}$ Download, como auxílio para esta problemática, possibilitando que educadores tenham uma formação continuada em que o conhecimento adquirido auxiliará na gravação de videoaulas a serem disponibilizadas aos estudantes da rede municipal de ensino.

\section{Metodologia}

Visando a preparação de professores para o ensino remoto, este estudo de natureza exploratório, investiga os efeitos de um encontro online, através da plataforma Google Meet, com quarenta e nove professores da rede municipal da cidade de Riacho de Santana no Estado do Rio Grande do Norte. O propósito foi capacitar os professores para o ensino remoto, lhes proporcionando as TIC como um caminho no enfrentamento aos problemas causados pela pandemia.

Inicialmente, foi exposto a importância das Tecnologias de Informação e Comunicação para o ensino remoto numa perspectiva de proposta de expansão da sala de aula, que possibilita o aluno estudar em qualquer lugar e no horário que ele desejar, a depender da sua necessidade. Em seguida, foram apresentados os programas: Vegas Pro 17, OBS Studio e $4 \boldsymbol{k}$ Downloader, de modo a auxiliar aos docentes nessa nova modalidade de ensino. Por meio desta formação remota, ocorreu a produção de um material em forma de tutorial, de forma a prestar assistência quando necessário.

O programa $\boldsymbol{O B S}$ Studio, refere-se a um software gratuito, que possibilita a gravação de tela e áudio, se encontra disponível para download no Windows (PC), no MacOS e no Linux, como pode ser visto na Figura 1.

Figura 1 - OBS Studio compatível com Windows, Mac OS e Linux.

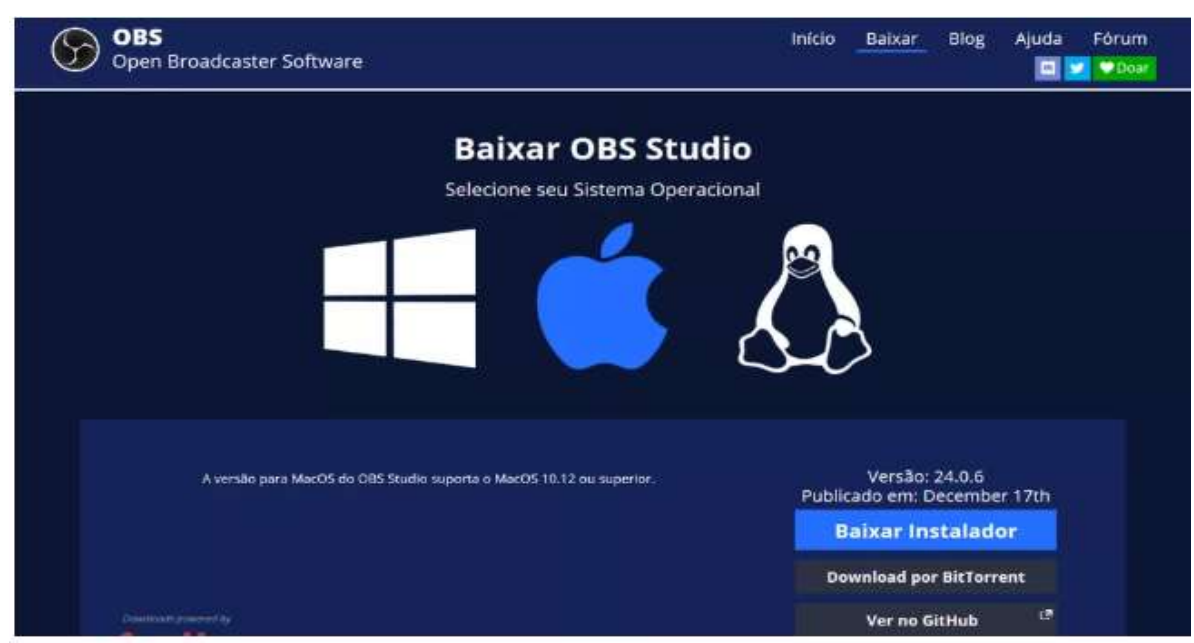

Fonte: Autores.

Por sua vez, o software 4 K Downloader é composto por uma série de aplicativos especializados em baixar vídeos e aúdios em alta definição, em questão de segundos. Pode ser utilizado no Windows, McOS e Linux. Realizado o download 
do programa o seu uso é simples, a sua tela inicial pode ser observada na Figura 2. O docente escolhe o vídeo que deseja baixar, copia o link e cola no software. O usuário também tem a opção de utilizar os atalhos $\mathbf{C t r l}+\mathbf{C}$ e $\mathbf{C t r l}+\mathbf{V}$.

No caso do software Vegas Pro 17, ele se encontra disponível somente para o sistema operacional do Windows 10, em uma versão de 64 bits. Este programa é utilizado quando se objetiva a edição de um vídeo com alta qualidade, na qual o manejo do áudio é realizado adequadamente. A Figura 3 mostra a tela inicial.

Figura 2 - Tela inicial do Software $4 K$ Downloader.

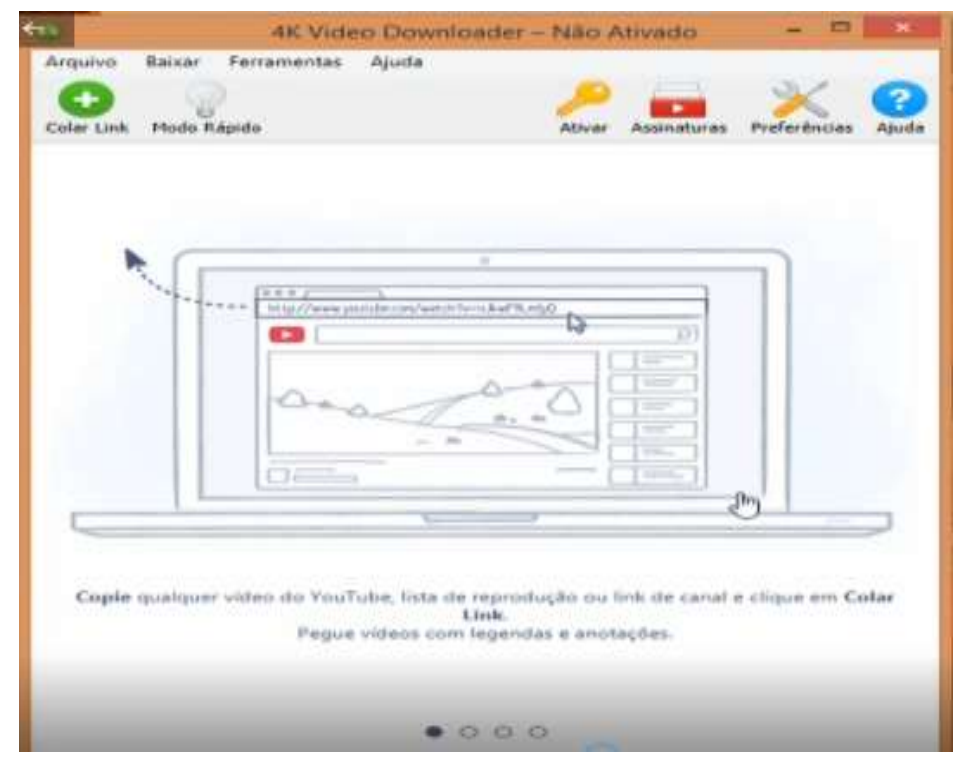

Fonte: Autores.

Figura 3 - Tela inicial do Vegas Pro.

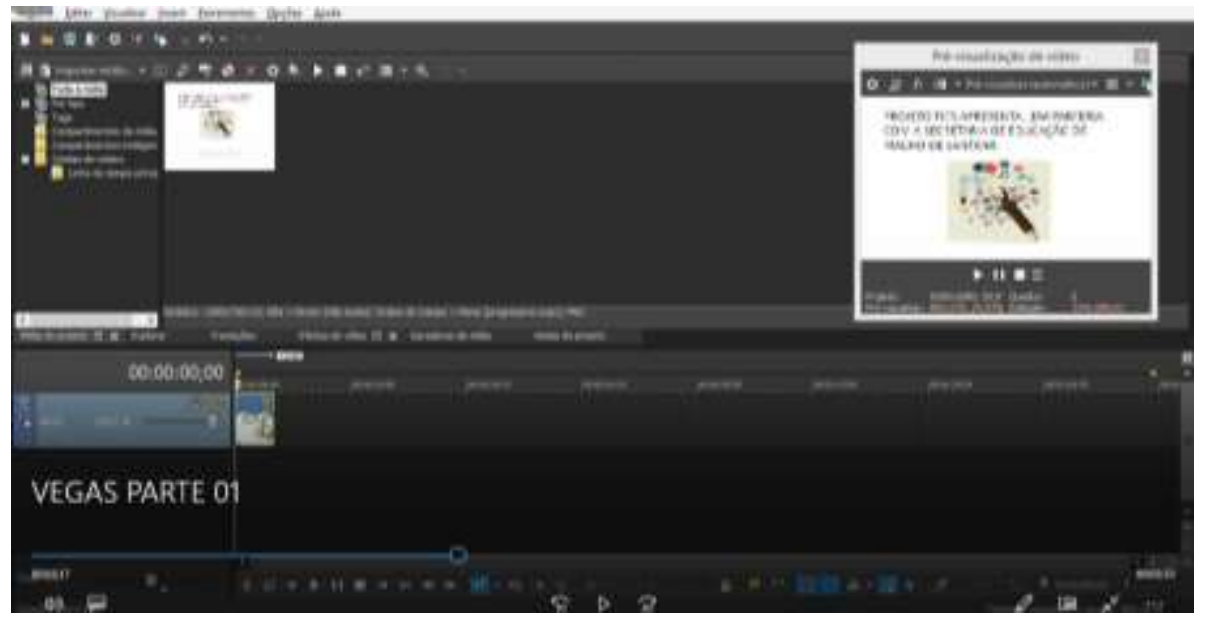

Fonte: Autores.

Na seção seguinte, são apresentados mais detalhes sobre os softwares utilizados, bem como a análise dos vídeos elaborados pelos professores após a formação.

\section{Resultados e Discussão}

No encontro remoto, ocorreu a abordagem dos softwares Vegas Pro 17, OBS Studio e 4 K Downloader que auxiliarão nas gravações de videoaulas pelos professores da rede municipal de ensino. 
Antes de iniciar a gravação da aula, é necessário configurar a tela de gravação do $\boldsymbol{O B S}$ Studio. Para isso, na tela inicial, clicando na opção "configuração", uma nova aba é aberta. No menu "Saída", determina-se o local onde o vídeo será salvo, por meio na opção “Caminho de gravação", em seguida "Localizar”, como mostra a Figura 4. É determinado também o formato de gravação, sendo mais utilizado o mp4, em seguida “Aplica” e confirma "Ok”.

Figura 4 - Configuração do local onde o arquivo será salvo.

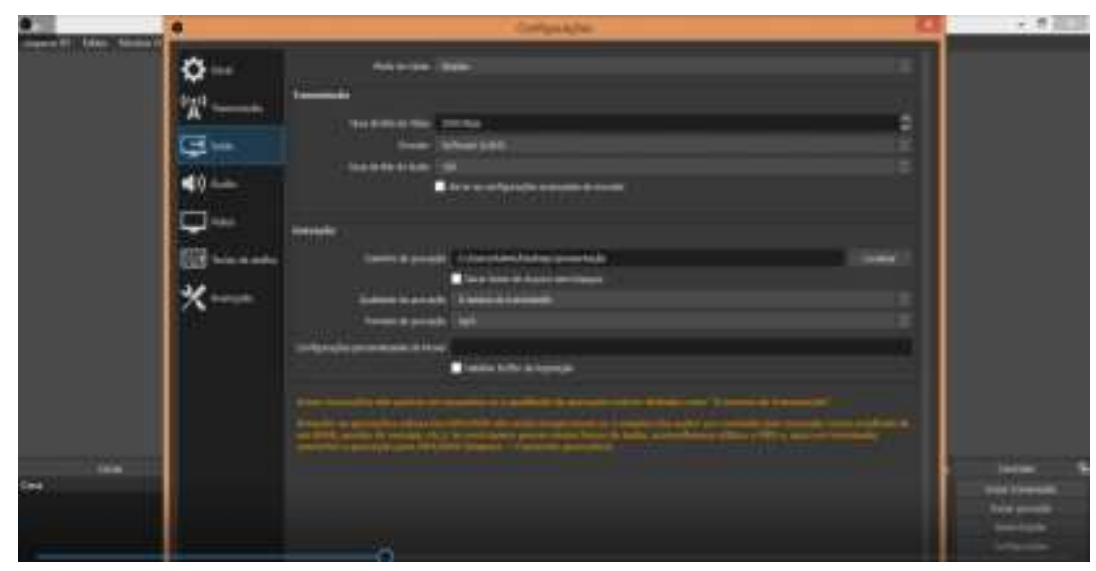

Fonte: Autores.

Os ajustes de áudio, também ocorre na seção de "Configuração", desta vez no menu "Áudio". É feito a determinação do microfone que será utilizado na gravação, através da opção "Dispositivo de áudio Mic/Auxiliar”, em seguida “Aplica” e confirma "Ok", como mostra a Figura 5.

Após realizar toda a configuração, é possível realizar a adição das ferramentas que serão utilizadas na gravação. No caso do microfone ocorre na seção "Fontes". O usuário clica com o botão direito, seleciona a opção "Adicionar" e em seguida escolhe a opção "Captura de Entrada de Áudio", que irar permitir a gravação da sua voz, de acordo com a Figura 6. Em seguida clica em "Ok".

Figura 5 - Configuração de áudio.

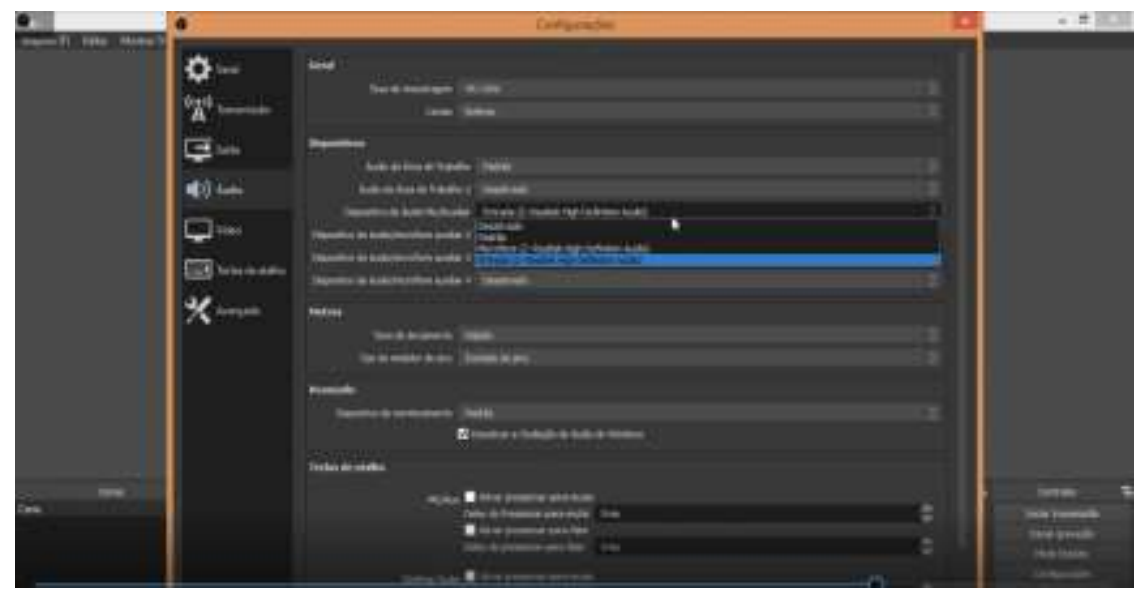

Fonte: Autores. 
Figura 6 - Primeiro passo para adição do microfone.

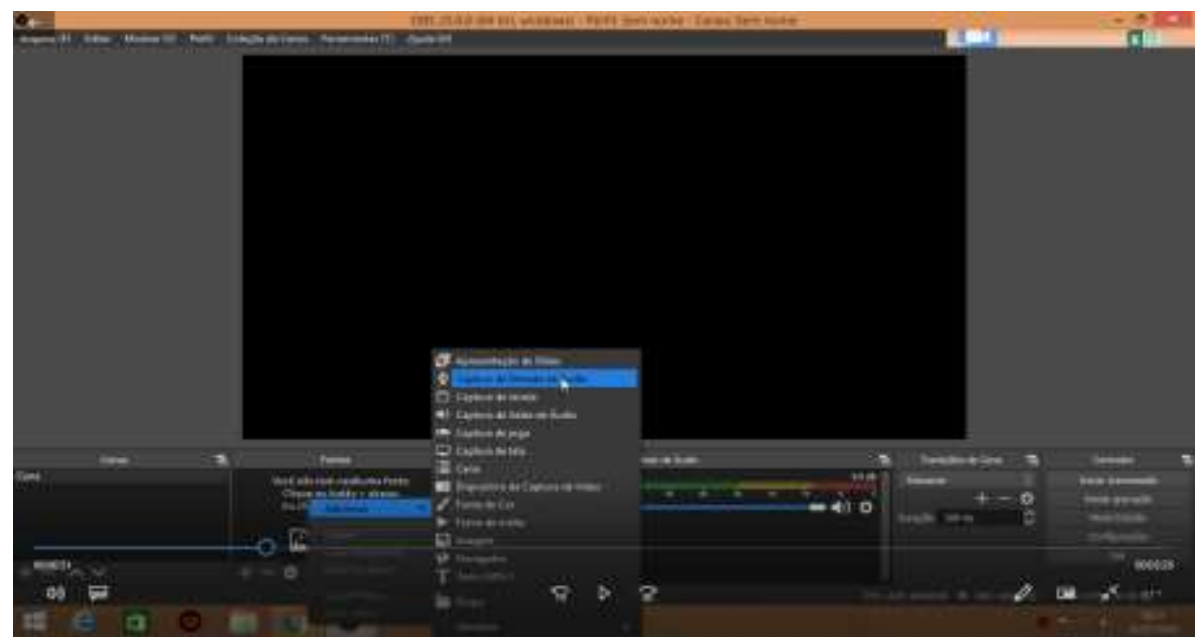

Fonte: Autores.

O passo seguinte consiste na seleção do microfone que será utilizado para capturar a voz, seleciona a opção "Microfone (2 - Realtek High Definition Audio)", como pode ser visto na Figura 7, em seguida a opção "Ok".

Ainda na seção "Fontes", é feito a gravação da tela, está pode ser feita de duas formas. A primeira seria através da opção "Captura de tela", como mostra a Figura 8, que permite transmitir o conteúdo de tudo que estiver aparecendo na tela. E a segunda alternativa seria "Captura de janela", como mostra a Figura 9, que permitirá a transmissão das janelas abertas no PC, deixando a critério do usuário o que será exibido. Logo após confirma a opção escolhida "Ok”.

Figura 7 - Segundo passo para adição do microfone.

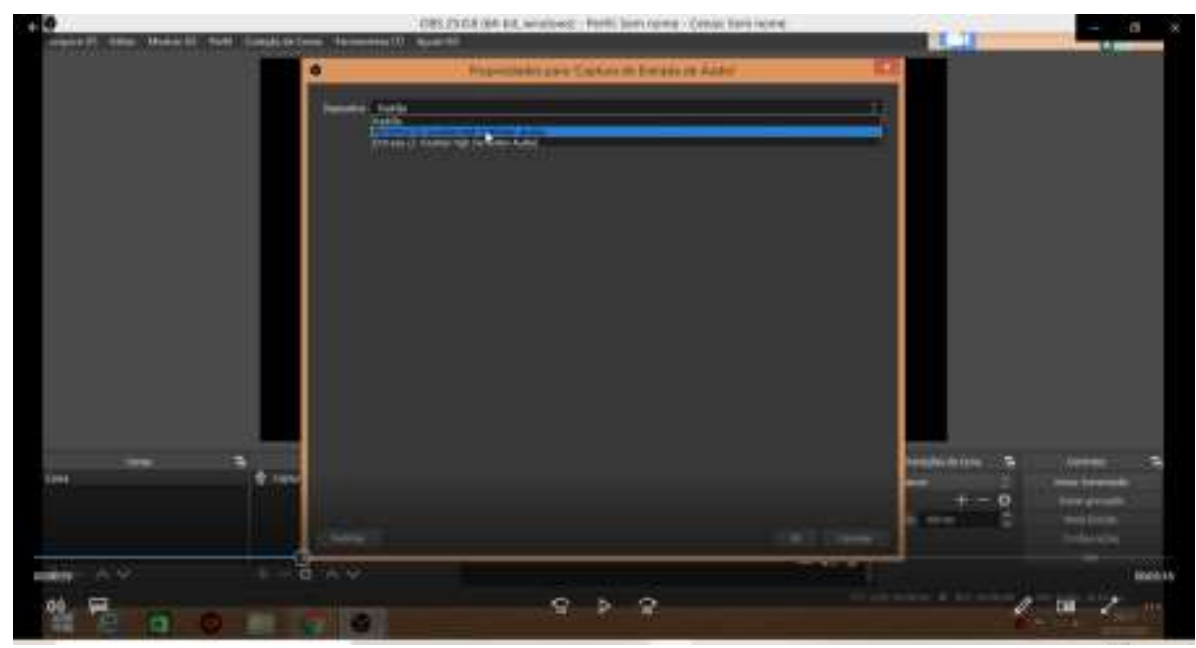

Fonte: Autores. 
Figura 8 - Primeiro passo para gravação de tela, opção "Captura de tela".

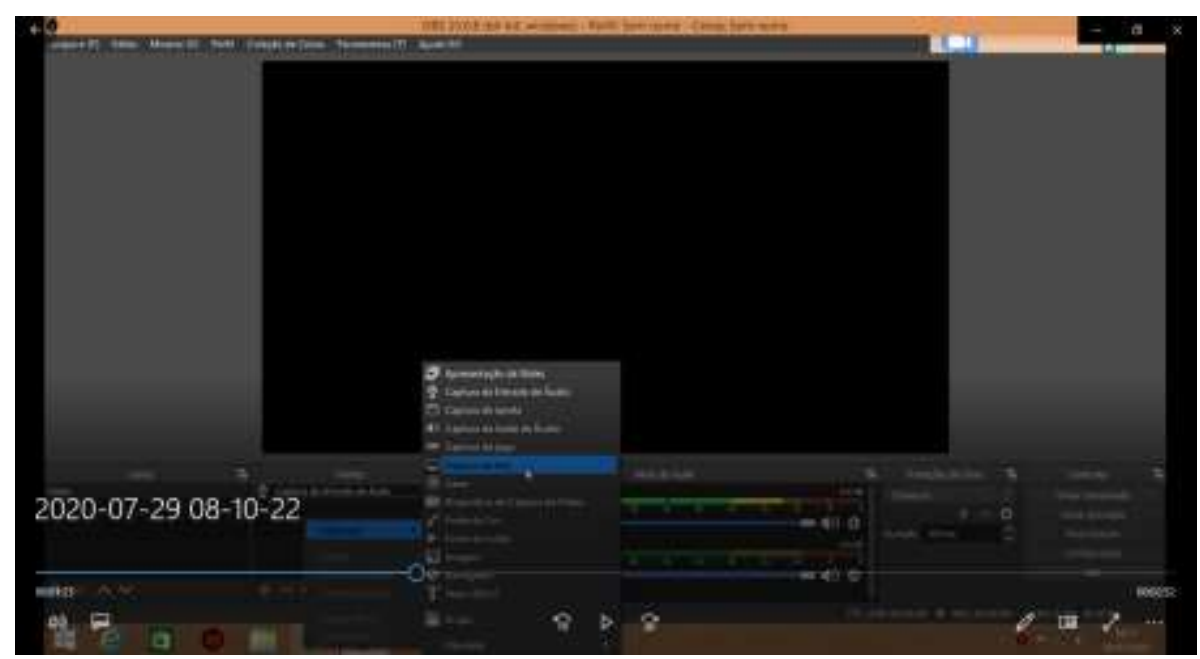

Fonte: Autores.

Figura 9 - Primeiro passo para gravação de tela, opção "Captura de janela".

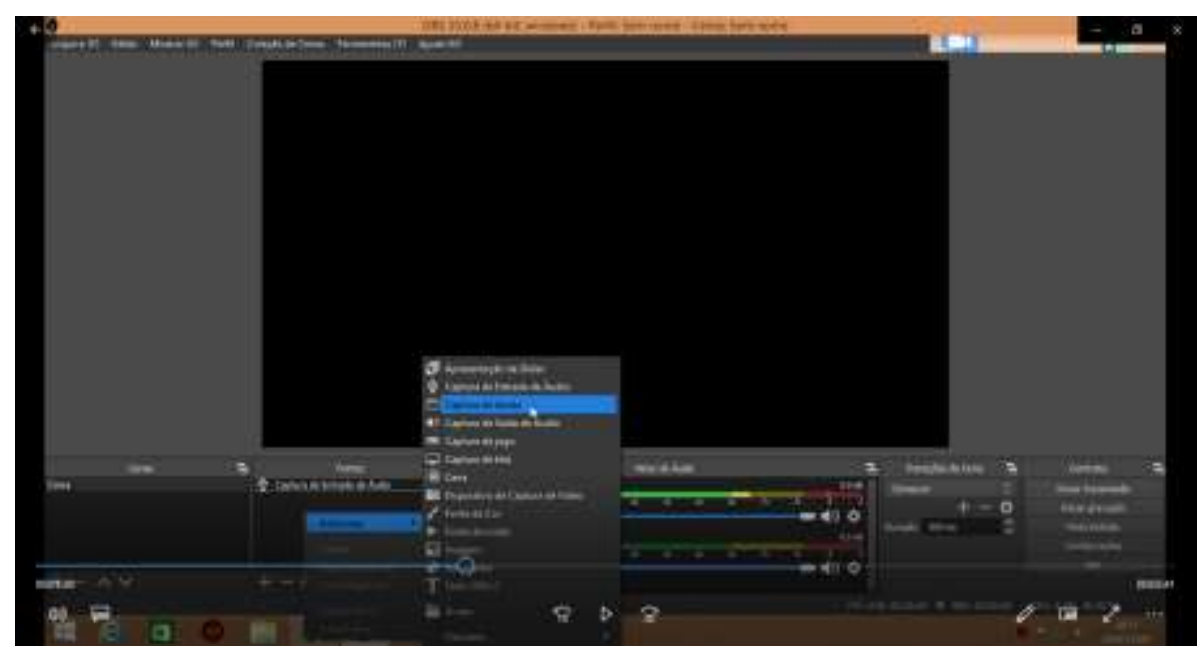

Fonte: Autores.

Caso a opção escolhida seja "Captura de janela", seguinte a sua confirmação será aberta uma nova aba, representada na Figura 10, na qual o usuário, na opção "Janela", escolherá qual deseja transmitir. Logo após confirma, "Ok".

Novamente na seção "Fontes", clicando com o botão direito e selecionando a opção "Adicionar", pode-se adicionar uma webcam, desta vez selecionando "Dispositivo de captura de vídeo", como é representado na Figura 11. Em seguida confirma o procedimento, "Ok". Abrirá uma nova aba, contendo as propriedades, como dispositivo responsável pela captura de vídeo e suas configurações, como tipo de resolução, FPS (frames por segundo) e formato de vídeo, como mostra a Figura 12, o passo seguinte é a confirmação, "Ok". 
Research, Society and Development, v. 10, n. 6, e37510615744, 2021

(CC BY 4.0) | ISSN 2525-3409 | DOI: http://dx.doi.org/10.33448/rsd-v10i6.15744

Figura 10 - Segundo passo para gravação, a escolha da que será transmitida. Caso a opção escolhida seja "Captura de janela".

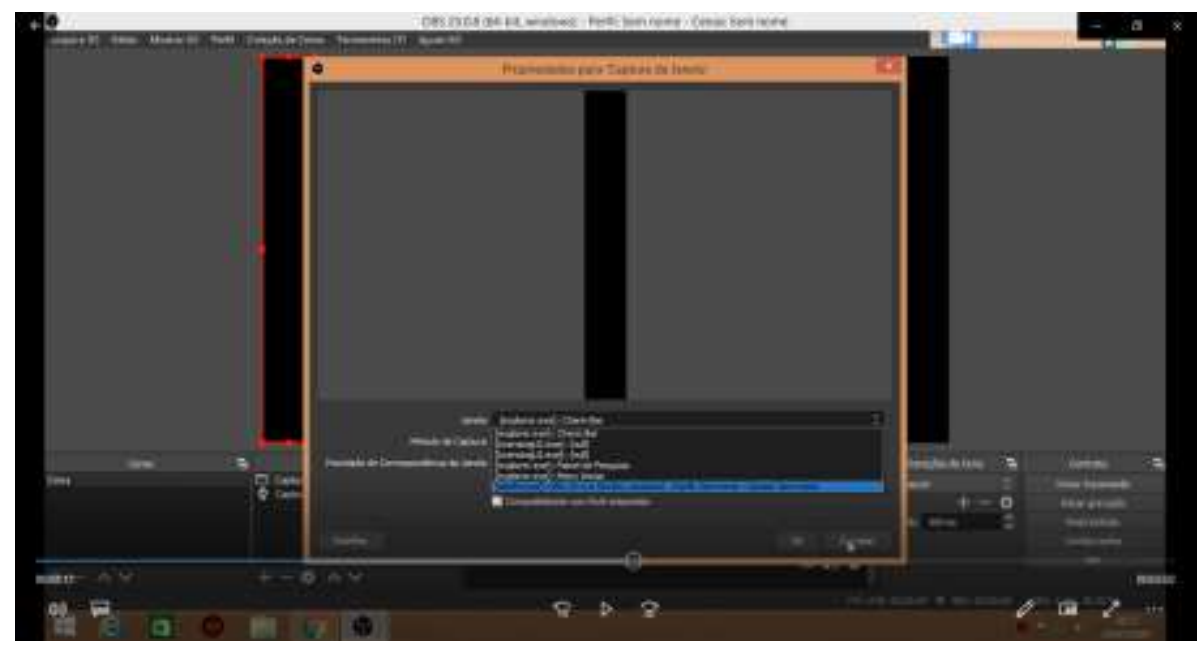

Fonte: Autores.

Figura 11 - Primeiro passo para adição da webcam.

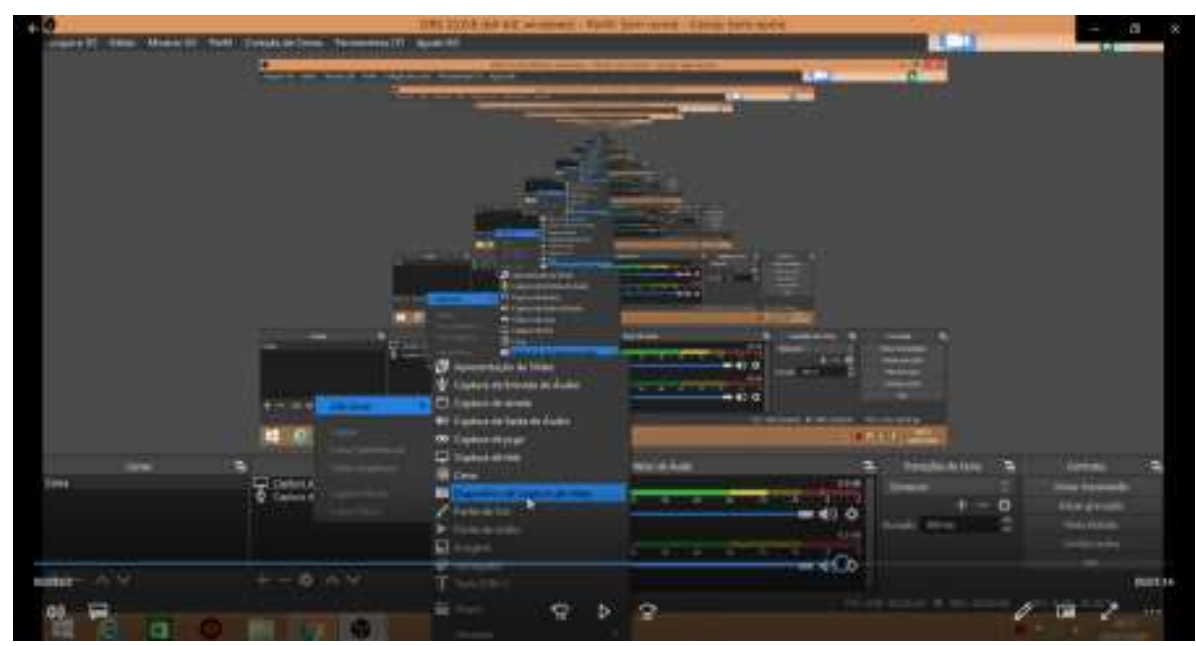

Fonte: Autores.

Figura 12 - Segundo passo para adição da webcam. Aba propriedades e configuração (quadrado em azul representa a webcam aberta).

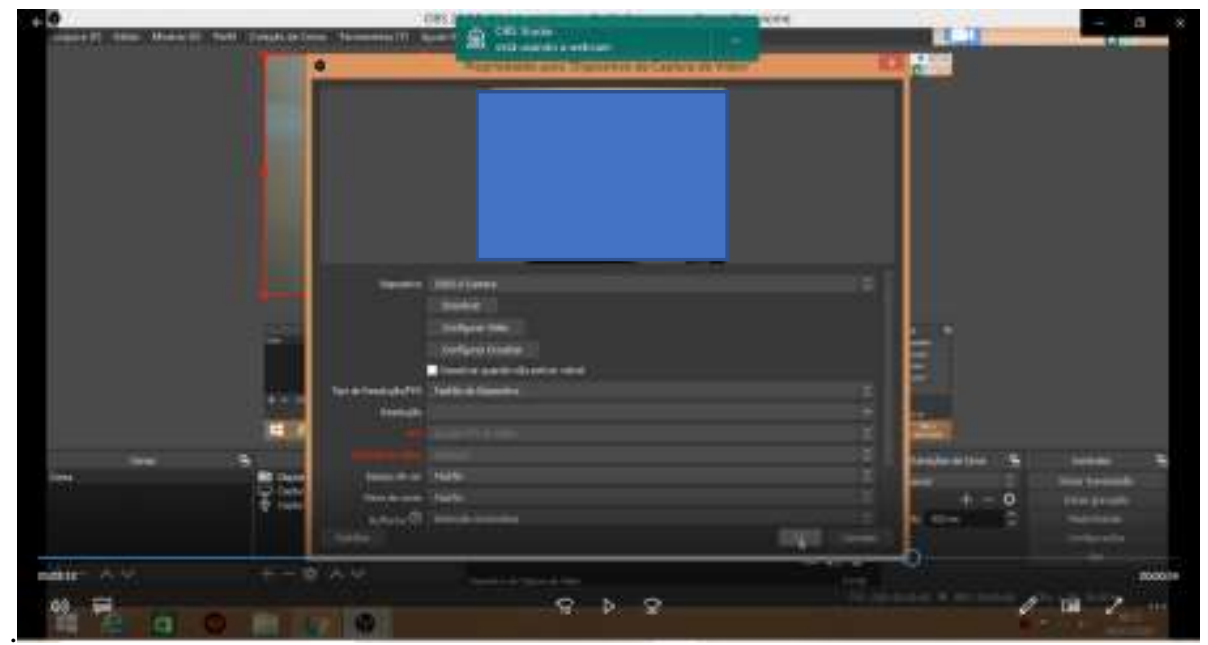

Fonte: Autores. 
As dimensões e localização da webcam ficam a critério do usuário. Realizando todos estes procedimentos, pode-se selecionar a opção "Iniciar a gravação", como é possível observar na Figura 13, que dará início a gravação. Para finalizar "Parar gravação", como mostra a Figura 14.

Figura 13 - Iniciar transmissão.

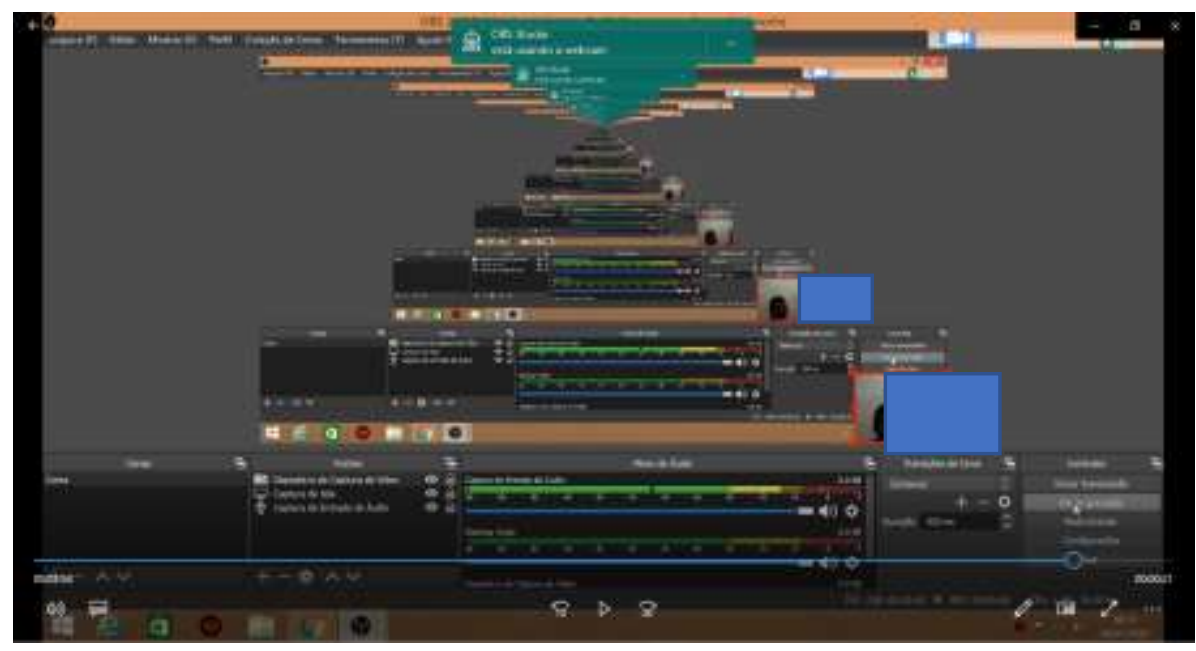

Fonte: Autores.

Figura 14 - Finalizar transmissão.

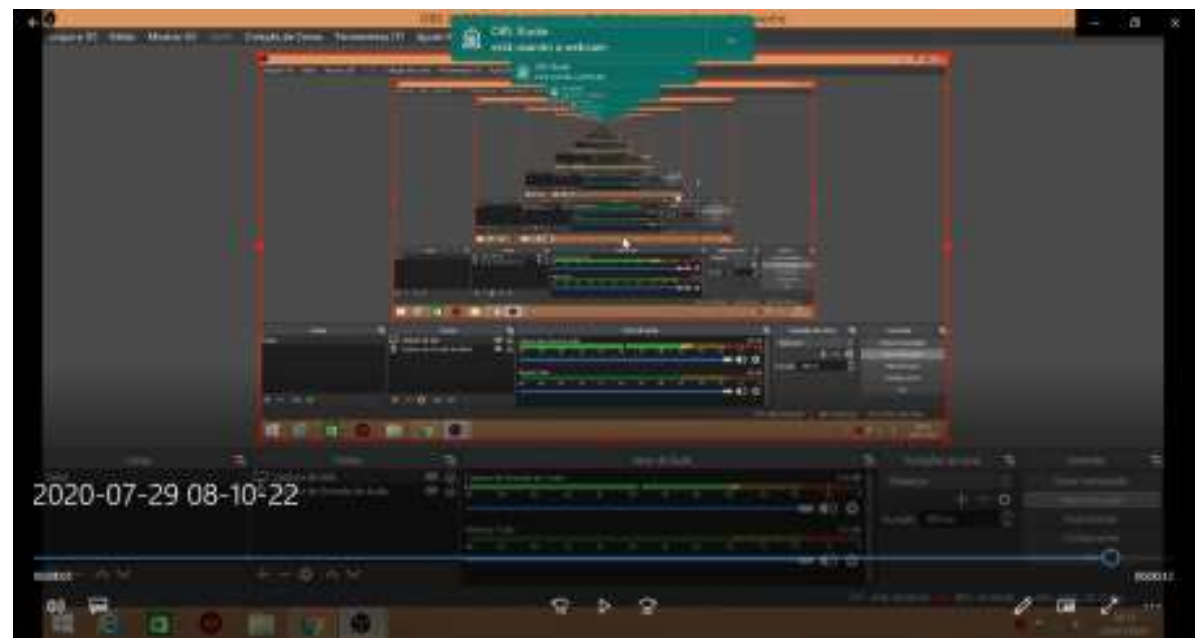

Fonte: Autores.

Por sua vez, o software 4K Downloader é composto por uma série de aplicativos especializados em baixar vídeos e aúdios em alta definição, em questão de segundos. Pode ser utilizado no Windows, McOS e Linux. Realizado o download do progama o seu uso é simples. O docente escolhe o vídeo que deseja baixar, copia o link e cola no software, o usuário também tem a opção de utilizar o atalho $\mathbf{C t r l}+\mathbf{C}$ e $\mathbf{C t r l}+\mathbf{V}$. Ocorrerá imediatamente a análise do vídeo.

Após a análise, abre-se uma aba com as características do vídeo a serem estabelecidas, Figura 15. É possível, desse modo, determinar o seu formato através da opção "Formato", usualmente se utiliza o mp4, como também a qualidade do vídeo, assim como local de armazenamento. Em seguida seleciona-se a opção "Baixar", e o arquivo será encaminhado para o destino determinado. 
Figura 15 - Definição das características.

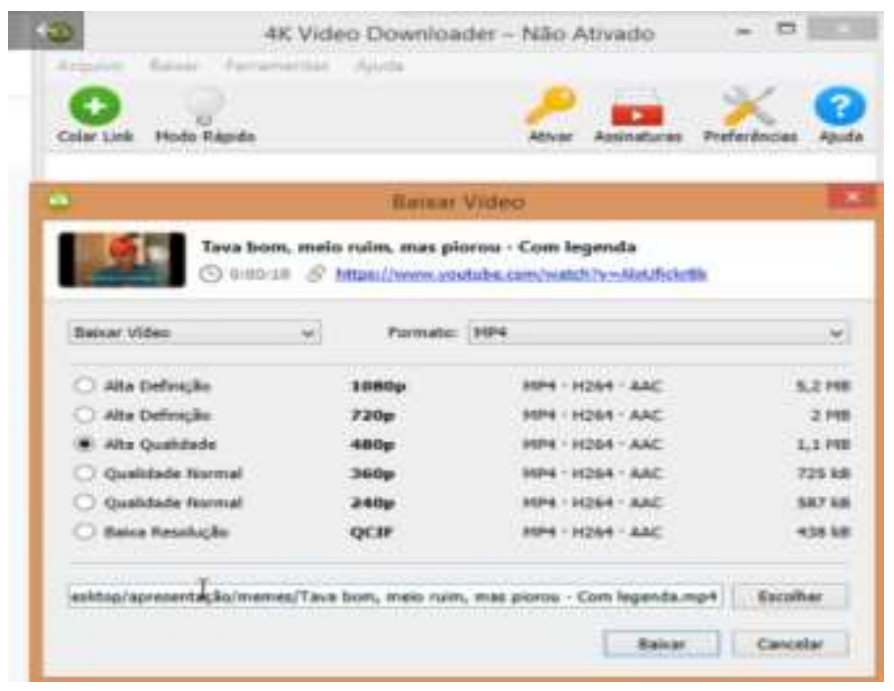

Fonte: Autores.

No caso do software Vegas Pro 17, ele se encontra disponível somente para o sistema operacional do Windows 10, em uma versão de 64 bits. Este programa é utilizado quando se objetiva a edição de um vídeo com alta qualidade, na qual o manejo do áudio é realizado adequadamente. Com o programa aberto, o processo de edição é simples. Caso o docente deseje inserir alguma imagem, ele pode simplesmente arrastar a imagem e soltar na tela inicial. Após este procedimento abrisse uma tela de pré-visualização, neste caso é preciso selecionar a opção "Play". No caso do vídeo o processo para inserir é semelhante ao de imagens, assim como o processo de reprodução.

Após realizar todo o procedimento de edição, para salvar o arquivo o docente seleciona a opção "Renderizar como", na parte superior da tela, no mesmo momento uma nova tela será aberta, contendo uma variedades de formatos, o mais comum é "MAGIX AVC/AAC MP4", assim como modelos, no caso para Youtube se recomenda "1080p de resolução à 50 fps", posteriormente escolhe o local onde o arquivo ficará e a clica na opção "Renderizar”, Figura 16.

Figura 16 - Procedimento para salvar arquivo no Vegas Pro 17.

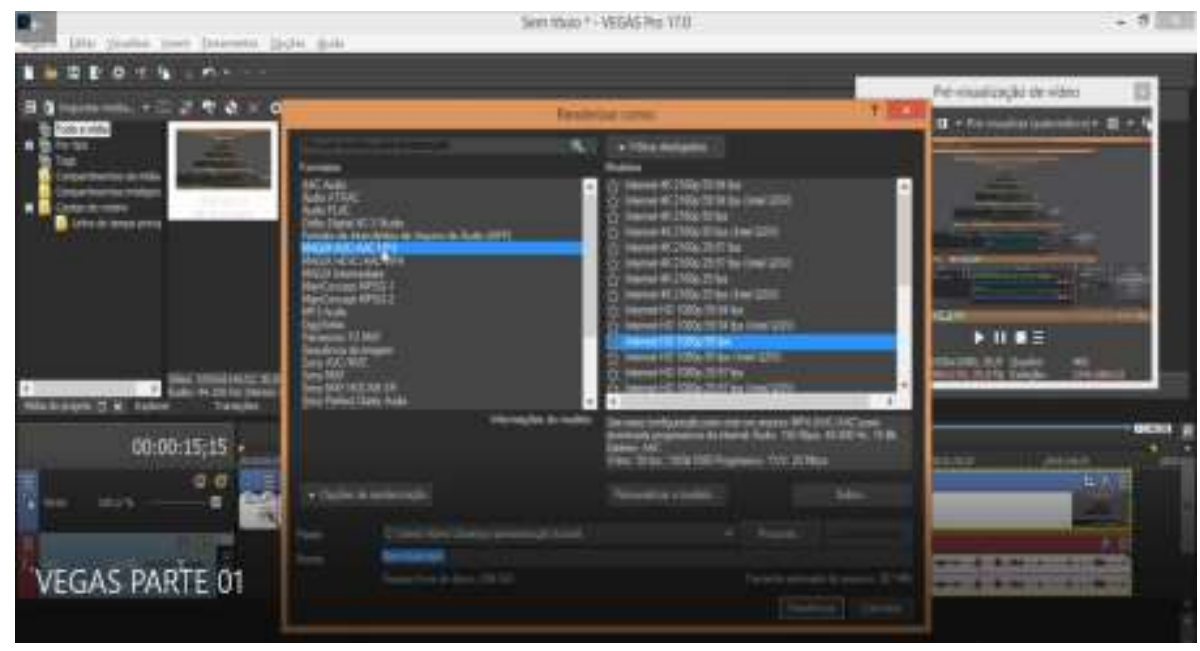

Fonte: Autores.

Caso o docente queria cortar o vídeo, como o botão direito do mouse, no local que se deseja realizar o corte, seleciona a opção "Dividir", outro modo é o atalho "S" do teclado. Quando for necessário apagar alguma parte, o usuário so precisa 
selecionar o que deseja excluir, clica na tecla "Delete" do teclado. Para inserir transição, o docente clica na opção "Transição", no mesmo momento vários modelos já aparecem, como mostra a Figura 17. O passo para inserir no vídeo é só arastar e soltar no local que deseja introduzir, em seguida clica na opção "Animar".

Figura 17 - Inserindo Transições no vídeo.

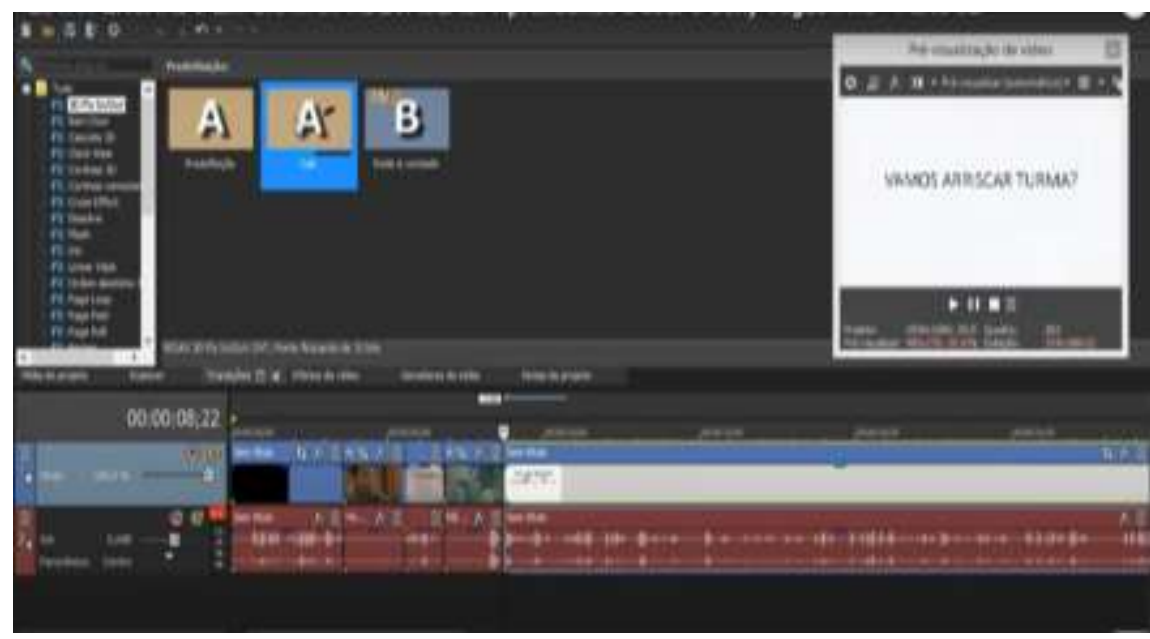

Fonte: Autores.

Uma outra propriedade do Vegas Pro 17, consiste na adição de textos. No entanto para isso o usuário precisa criar uma nova faixa de vídeo. Esse processo é feito com o botão direito do mousse, no canto esquerdo da tela, em seguida seleciona a opção "Inserir faixa de vídeo", como mostra a Figura 18. Após isto, posiciona-se o cursor no local onde deseja inserir o texto, com o botão direito do mousse seleciona a opção "Inserir mídia de texto", Figura 19, abrir-se uma aba destinada a escrita, contendo todas as propriedades que podem ser alteradas.

Figura 18 - Inserindo faixa de vídeo.

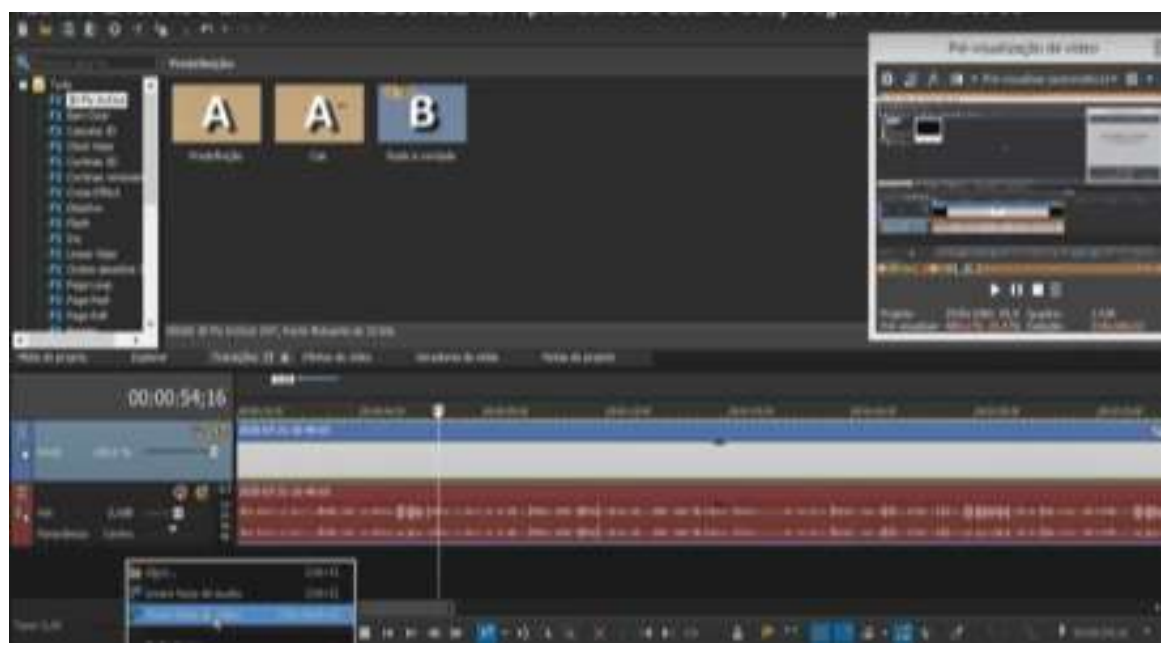

Fonte: Autores.

Realizando um processo semelhante é possível adicionar áudio ao vídeo que estar sendo produzido. Entretanto, ao invés da opção "Inserir faixa de vídeo", seria escolhido "Inserir faixa de áudio", feito isso o docente pode arrastar o arquivo, que já deve estar no computador, para o local que ele desejar. Fica a critério do usuário o volume. 
Figura 19 - Inserindo mídia de texto.

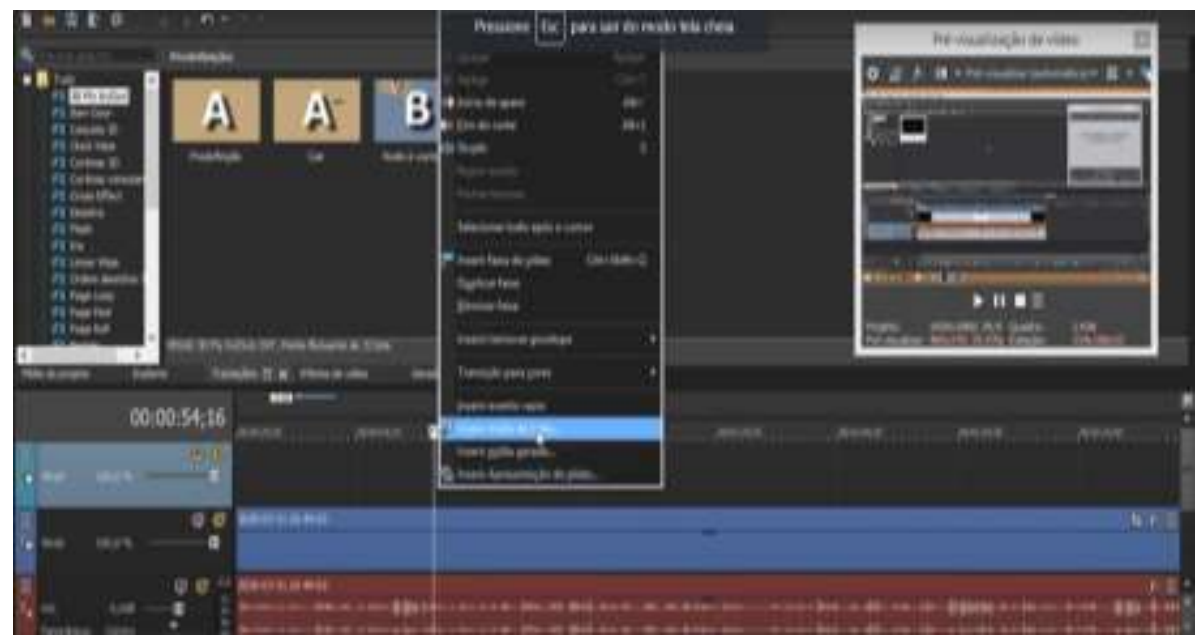

Fonte: Autores.

Finalizando a formação, os professores poderiam aplicar os conhecimentos em suas aulas gravando videoaulas a serem disponibilizadas para os discentes. Notou-se mudanças extremamente significativa no que se refere a inclusão digital nas escolas, que, devido a pandemia, tornou-se a principal fonte de ensino e interação entre escola e aluno.

No começo do retorno as aulas remotas devido ao COVID-19, as mesmas eram repassadas aos alunos por imagem (fotos) e áudio explicando o conteúdo e a atividade a ser feita, onde a maioria dos alunos não entendiam e não achavam as aulas remotas interessantes e nem informativas, onde os mesmos achavam que brincar e assistir seus vídeos preferidos eram mais apropriados do que estudar em casa com um método "ultrapassado" e desinteressante.

Os programas foram bem aceitos pela secretaria municipal de educação e professores e foi disponibilizado um tutorial detalhando a forma de configurar, editar, gravar e postar as vídeo aulas.

Após algumas semanas aplicando os vídeos aulas, notou-se uma melhora muito significativa da participação dos alunos nas aulas. Os métodos de vídeos fizeram-se com que os alunos tivessem interesse em assistir e estudar, além de não ser tão cansativo como áudios e fotos. A secretaria relatou também uma grande mudança na equipe no que se refere aos vídeos, onde todos se ajudam para um melhor conteúdo e uma edição que deixa os alunos mais interessados na aula e participam intensamente, levando a uma melhor aprendizagem.

\section{Considerações Finais}

Com o surgimento do novo coronavírus, a Organização Mundial de Saúde, tem defendendo como principal medida de controle da disseminação do COVID-19, o distanciamento social, fazendo com que inúmeras atividades, como o comércio e os serviços educacionais sejam impactados.

Diversos países adotaram como uma das medidas de controle do avanço do novo coronavírus, a proibição de atividades de ensino na modalidade presencial, fazendo com que as aulas ocorram de forma remota, tendo as Tecnologias da Informação e Comunicação como grande aliada do processo de ensino-aprendizagem. No entanto, percebeu-se que muitos dos docentes não estavam preparados para essa modalidade de ensino, fazendo-se necessário um esforço maior com a formação desses profissionais.

Pensando em melhorar a formações dos profissionais da educação básica, foi realizada uma formação junto aos professores da rede municipal de ensino de Riacho de Santana - RN, tendo como objetivo apresentar ferramentas que os docentes poderiam utilizar em suas aulas, sendo estas os softwares Vegas Pro 17, OBS Studio e 4k download. 
No primeiro momento da formação foram apresentados os softwares em questão, e no segundo momento, foram descritos os procedimentos básicos que poderiam ser utilizados nos processos de gravação e edição das aulas. Por fim, os docentes receberam vídeos com tutoriais resumindo a utilização dos softwares abordados na formação.

Ao final do trabalho percebeu-se uma melhoria significativa na qualidade das aulas, inicialmente alguns professores trabalhavam com áudios que eram encaminhados via Whastssap para os estudantes ou responsáveis. Com a formação e o conhecimento nos softwares apresentados, os docentes foram capazes de planejar, gravar e editar videoaulas para serem encaminhadas aos discentes, atuando assim com encaminhamentos metodológicos mais interativos, e consequentemente, mais produtivos.

Como sugestões para trabalhos futuros, tem-se relatos de dificuldades enfrentadas pelo corpo docente mediante o ensino remoto, metodologias adotadas por professores para o ensino remoto em tempos de pandemia, assim como as vantagens da utilização das TICs na metodologia adotada por professores em ensino remoto.

\section{Agradecimentos}

Os autores agradecem à Universidade Federal Rural do Semi-árido - UFERSA e a Pró-Reitoria de Extensão da UFERSA pelo apoio financeiro ao projeto PJ129-2019, à Coordenação de Aperfeiçoamento de Pessoal de Nível Superior CAPES, à Prefeitura Municipal de Riacho de Santana, à Secretaria Municipal de Educação de Riacho de Santana e à Escola Municipal João Bernardino de Lima.

\section{Referências}

Anderson, R. M., Heesterbeek, H., Klinkenberg, D., \& Hollingsworth, T. D. (2020). How will country-based mitigation measures influence the course of the COVID-19 epidemic? The lancet, 395(10228), 931-934.

Appenzeller, S., Menezes, F. H., Santos, G. G. D., Padilha, R. F., Graça, H. S., \& Bragança, J. F. (2020). Novos tempos, novos desafios: estratégias para equidade de acesso ao ensino remoto emergencial. Revista Brasileira de Educação Médica, 44.

Arruda, E. P. (2020). Educação remota emergencial: elementos para políticas públicas na educação brasileira em tempos de Covid-19. EmRede-Revista de Educação a Distância, 7(1), 257-275.

Associação Brasileira de Educação a Distância (Abed), 2008. O que é educação a distância? ABED. http://www.abed.org.br/site/pt/faq/.

Bueno, E. C., \& Gama, M. E. R. (2021). The performance of managers who work in socio-educational spaces in the pandemic. Research, Society and Development, 10(4), e17110414012. https://doi.org/10.33448/rsd-v10i4.14012

Campanha Nacional Pelo Direito À Educação. 8 motivos para não substituir a educação presencial pela educação a distância (EaD) durante a pandemia. https://campanha.org.br/noticias/2020/03/26/8-motivos-para-nao-usar-educacao-distancia-ead-como-alternativa-para-substituir-educacao-

presencial/?fbclid=IwAR1eSfo1V_T--kEmQYGOG5hEfEoIt1Mavy8368FHsqBqxBSa-idbsW_nsVs .

Carcamo, M., Stumpf, E. R. T., \& Mariot, M. P. (2020). Avaliação de servidores em Educação sobre condições de risco para a COVID-19. Revista Thema, 18, 111-123.doi:http://dx.doi.org/10.15536/thema.V18.Especial.2020.111-123.1825.

Castaman, A. S., \& Szatkoski, E. (2020). Distance education in the context of professional and technological education: considerations in pandemic times. Research, Society and Development, 9(7), e491974399. https://doi.org/10.33448/rsd-v9i7.4399.

Feitosa, M. C., de Souza Moura, P., Ramos, M. D. S. F., \& Lavor, O. P. (2020, July). Ensino Remoto: O que Pensam os Alunos e Professores? In: Anais do V Congresso sobre Tecnologias na Educação (pp. 60-68). SBC. https://sol.sbc.org.br/index.php/ctrle/article/view/11383/11246.

Fernandes, A. V., Oliveira, M. T. De, Aquino, A. A. De; Farias, A. D. S., \& Lavor, O. P. (2020). Uso do aplicativo mestre da matemática como recurso didático na educação básica. In: Anais do Congresso Nacional de Pesquisa em Ensino de Ciências - CONAPESC, V. Realize Editora. http://editorarealize.com.br/artigo/visualizar/72766.

Garcia, L. P., \& Duarte, E. (2020). Intervenções não farmacológicas para o enfrentamento à epidemia da COVID-19 no Brasil. https://doi.org/10.5123/s167949742020000200009.

Lewnard, J. A., \& Lo, N. C. (2020). Scientific and ethical basis for social-distancing interventions against COVID-19. The Lancet Infectious Diseases, 20(6), 631-633. https://www.thelancet.com/action/showPdf?pii=S1473-3099\%2820\%2930190-0. / .

Limeira, M. A. (2017). A utilização das TICS na educação infantil. 
Research, Society and Development, v. 10, n. 6, e37510615744, 2021

(CC BY 4.0) | ISSN 2525-3409 | DOI: http://dx.doi.org/10.33448/rsd-v10i6.15744

Lopes, A. F., dos Santos, É. M. B. R., Ferreira, P. J. S., \& Brito, P. V. G. (2011). O desafio do uso das tic na educação infantil. Revista Pandora Brasil.34(1), $170-184$.

Mourão, L. dos S., Araújo, L. C., Silva, M. P. da (2019). "Educação virtual e marketing digital: uma análise do perfil "Efeito Orna" no Instagram". Revista Tecnologias na Educação, 30, 1-13. https://tecedu.pro.br/wp-content/uploads/2019/12/Art1-Ano-11-vol30-Novembro-2019.pdf .

Reis, A. T. V. (2016). A importância das TICs e da educação como processo comunicacional dialógico no ensino superior: um estudo da Universidade Estadual de Mato Grosso do Sul.

Rondini, C. A., Pedro, K. M., \& dos Santos Duarte, C. (2020). Pandemia do Covid-19 e o ensino remoto emergencial: Mudanças na práxis docente. Interfaces Científicas-Educação, 10(1), 41-57.

Rosa, R., \& Cecilio, S. (2010). Educação e o uso pedagógico das tecnologias da informação e comunicação: a produção do conhecimento em análise. Revista Educação em Foco, Juiz de Fora. 15(1), 107-26.

UNESCO. 2020. COVID-19: Impact on Education. https://en.unesco.org/covid19/educationresponse.

Vieira, L. F. K. (2015). EaD na contabilidade: uma análise de sua efetivação de uso no curso de Ciências Contábeis da Universidade Federal do Rio Grande do Sul. 